\title{
Left ventricular pacing lead insertion via the coronary sinus cardioplegia cannula: A novel method for temporary biventricular pacing during reoperative cardiac surgery
}

\author{
Daniel Y. Wang, MD, ${ }^{\mathrm{a}}$ Rabin Gerrah, MD, ${ }^{\mathrm{b}}$ Alexander Rusanov, MD, ${ }^{\mathrm{b}}$ Vinay Yalamanchi, BA, \\ Santos E. Cabreriza, MBA, ${ }^{\mathrm{b}}$ and Henry M. Spotnitz, MD $^{\mathrm{b}}$
}

\begin{abstract}
Objective: Temporary biventricular pacing to treat low output states after cardiac surgery is an active area of investigation. Reoperative cases are not studied due to adhesions, which preclude left ventricular mobilization to place epicardial pacing wires. In such patients, inserting a temporary left ventricular lead via the coronary sinus cardioplegia cannula may allow for biventricular pacing. We developed a novel technique for intraoperative left ventricular lead placement.
\end{abstract}

\begin{abstract}
Methods: Eight domestic pigs underwent median sternotomy and pericardiotomy. Temporary pacing wires were sewn to the right atrium and right ventricle. Complete heart block was induced by ethanol ablation of the atrioventricular node. A 13-French retrograde cardioplegia catheter was introduced via the right atrial free wall into the coronary sinus. A 6-French left ventricular pacing lead was inserted into the cardioplegia catheter and advanced into the coronary sinus during biventricular pacing until left ventricular capture was detected by electrocardiogram and arterial pressure monitoring. Left ventricular capture success rate and electrical performance were recorded during five placement attempts.
\end{abstract}

Results: Left ventricular capture was achieved on $80 \%$ of insertion attempts. Left ventricular capture without diaphragmatic pacing was achieved in 7 pigs. Lead tip locations were mostly in lateral and posterior basal coronary vein branches. There were no arrhythmias, bleeding, or perforation associated with lead insertion.

Conclusions: Intraoperative biventricular pacing with a left ventricular pacing lead inserted via the coronary sinus cardioplegia cannula is feasible, using standard instrumentation and without requiring cardiac manipulation. This approach merits further study in patients undergoing reoperative cardiac surgery. (J Thorac Cardiovasc Surg 2011;142:73-6)

In select patients with congestive heart failure (CHF), cardiac resynchronization therapy with biventricular pacing (BiVP) reduces morbidity. ${ }^{1-4}$ Permanent BiVP is indicated in advanced, chronic CHF associated with left ventricular (LV) dysfunction and intraventricular conduction delay. ${ }^{5}$ The use of BiVP acutely improves cardiac contractility and cardiac output without increasing myocardial energy consumption. ${ }^{6,7}$ Therefore, it represents a potential treatment for low output heart failure after cardiac surgery, in which low ejection fraction is a strong predictor of poor postoperative outcomes. ${ }^{8,9}$

\footnotetext{
From the Departments of Medicine ${ }^{\mathrm{a}}$ and Surgery, ${ }^{\mathrm{b}}$ Columbia University, New York, NY.

Funded by a startup grant from the Department of Surgery at Columbia University. Dr Wang is supported by the National Institutes of Health Training Grant No. T32 HL007854.

Disclosures: Dr Spotnitz is the Principal Investigator on the NIH RO1 Grant HL080152, "Biventricular Pacing After Cardiopulmonary Bypass." He is also a member of the Scientific Advisory Board of Biophan Technologies, Inc.

Received for publication March 19, 2010; revisions received June 25, 2010; accepted for publication Aug 1, 2010; available ahead of print Oct 21, 2010

Address for reprints: Henry M. Spotnitz, MD, Department of Surgery, Columbia University Medical Center, 622 W 168th St, Vanderbilt Clinic, 10th Floor, Room 1010, New York, NY 10032 (E-mail: hms2@columbia.edu).

$0022-5223 / \$ 36.00$

Copyright (c) 2011 by The American Association for Thoracic Surgery

doi:10.1016/j.jtcvs.2010.08.028
}

Temporary BiVP in the perioperative cardiac surgery setting is an active area of investigation, with numerous trials demonstrating acute improvements in cardiac output, arterial pressure, and ventricular synchrony. ${ }^{10-18}$ To be able to achieve BiVP, such protocols involve attaching temporary pacing wires to the right atrial (RA), right ventricular (RV), and LV epicardium. An important limitation to this approach occurs in the setting of reoperative cardiac surgery, where adhesions preclude adequate mobilization of the heart to place pacing wires on the lateral or posterior LV. Patients with reduced ejection fraction who are undergoing reoperative surgery comprise a particularly high-risk group ${ }^{19}$ and may especially benefit from temporary BiVP. Currently, such patients are excluded from the study. Consequently, development of an alternative method of achieving BiVP in these patients is needed. Here we report the feasibility and safety of a new technique for LV lead delivery via the coronary sinus (CS) cardioplegia cannula during open heart surgery.

\section{METHODS}

All animal studies were performed according to the National Institutes of Health Guide for the Care and Use of Laboratory Animals. The experimental protocol was approved by the Columbia University Institutional Animal Care and Use Committee. 


$$
\begin{aligned}
& \text { Abbreviations and Acronyms } \\
& \mathrm{BiVP}=\text { biventricular pacing } \\
& \mathrm{CHF}=\text { congestive heart failure } \\
& \mathrm{CS}=\text { the coronary sinus } \\
& \mathrm{ECG}=\text { electrocardiogram } \\
& \mathrm{LV}=\text { left ventricular } \\
& \mathrm{RA}=\text { right atrial } \\
& \mathrm{RV}=\text { right ventricular }
\end{aligned}
$$

Eight Yorkshire pigs ( $28-33 \mathrm{~kg}$ ) were anesthetized intramuscularly with atropine $(0.02 \mathrm{mg} / \mathrm{kg})$, ketamine $(20 \mathrm{mg} / \mathrm{kg})$, and xylazine $(0.5 \mathrm{mg} / \mathrm{kg})$, followed by oral endotracheal intubation and mechanical ventilation, as previously described..$^{20,21}$ Anesthesia was maintained with isoflurane $(1.75-2.5 \%)$ in oxygen. Arterial blood gas measurements were used to guide maintenance of adequate oxygenation and ventilation. Intravenous access was established via a posterior auricular vein, and $0.9 \%$ saline was administered at $5 \mathrm{~mL} / \mathrm{kg} / \mathrm{hr}$. A femoral arterial line was inserted to measure arterial pressure. Standard limb leads were placed for surface electrocardiogram (ECG) monitoring. Pulse oximetry was monitored from the shaved tail. After a median sternotomy, the pericardium was incised longitudinally and traction sutures were placed to expose and support the heart.

Bipolar temporary epicardial pacing leads (Medtronic 6495; Medtronic, Minneapolis, Minn) were sewn onto the RA appendage and anterior surface of the RV. The pacing leads were attached to a biventricular pacemaker (Medtronic InSync III) in a custom housing unit to allow lead connection with alligator clips. Proper lead function was then confirmed. Complete heart block was established with injection of $0.5 \mathrm{~mL}$ aliquots of $100 \%$ ethanol into the region of the bundle of His, at the base of the aorta, as previously described. ${ }^{22}$

A 13-French retrograde cardioplegia cannula was inserted via a RA free wall incision into the proximal CS and secured with a pursestring suture. Using the cardioplegia cannula as a guiding sheath, a 6-French bipolar LV pacing lead (Medtronic Attain 4194) with a stylet was inserted into the cardioplegia cannula and advanced into the CS. The LV lead was connected to the biventricular pacemaker, programmed at DDD 90 and an atrioventricular delay of $150 \mathrm{msec}$. Without lifting the heart, the lead was slowly advanced until LV capture was detected on ECG and confirmed by arterial pressure monitoring and visual inspection during LV pacing alone. Pacing function, including impedance and capture threshold, was measured with the stylet slightly withdrawn. If diaphragmatic stimulation was present, the lead was slowly advanced and empirically torqued clockwise or counterclockwise, as needed, until ventricular pacing without diaphragmatic stimulation was achieved, and thresholds and impedances were retested. Both bipolar and unipolar pacing configurations were tested to achieve the optimal pacing performance. After a minimum of 1-minute pacing, the lead was withdrawn from the cardioplegia cannula. Five insertion trials were tested for each animal. After the fifth trial, the heart was lifted and visually inspected for any evidence of bleeding or perforation, and the location of the LV lead tip was noted (Figure 1). ECG monitoring for arrhythmias was conducted throughout the experiment. The animals were humanely killed at the end of the experiment.

\section{RESULTS}

Capture success rates, electrical performance, and lead locations for each animal are shown in Table 1. There were no episodes of arrhythmia, bleeding, perforation, or hemodynamic compromise during lead placement attempts.

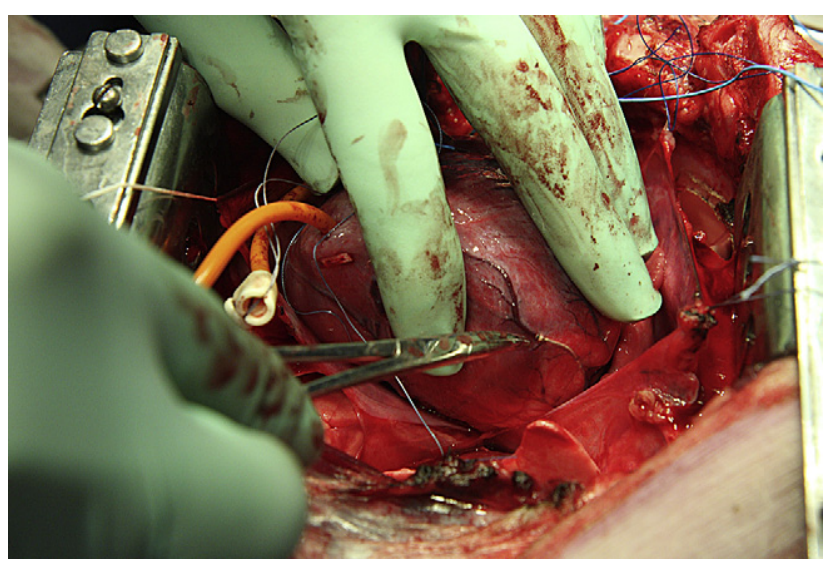

FIGURE 1. Inspection of the left ventricular (LV) lead location. In this example, the tip of the LV lead is seen in an epicardial venous branch off of the coronary sinus over the mid-lateral LV.

The overall capture success rate for all attempts was $80 \%$. The LV capture was achieved on at least one attempt in all 8 animals. In one animal, diaphragmatic pacing could not be avoided, despite lead repositioning and adjustment of pacing output and polarity. In the majority of animals, the LV lead tip was found to be in a coronary vein in the lateral or posterior aspect of the $\mathrm{LV}$ wall. The most common reason for failure to capture the $\mathrm{LV}$ was due to coursing of the $\mathrm{LV}$ lead into the left hemiazygous vein.

\section{DISCUSSION}

In patients with postoperative low output syndrome, temporary BiVP to improve hemodynamics and ventricular mechanics is an active area of investigation. ${ }^{10-18}$ Patients undergoing reoperative cardiac surgery comprise a particularly high-risk group. ${ }^{19}$ Thus, new techniques for temporary LV pacing are needed, so that the role of temporary BiVP can be studied in this cohort. To our knowledge, this is the first report of such a technique.

We demonstrate the feasibility and safety of a novel method for achieving temporary BiVP during open heart surgery. Our model replicates a common clinical technique

TABLE 1. Left ventricular lead location and electrical performance

\begin{tabular}{lcccl}
\hline Pig \# & $\begin{array}{c}\text { Capture success } \\
\text { rate (\%) }\end{array}$ & $\begin{array}{c}\text { Capture } \\
\text { threshold (V) }\end{array}$ & $\begin{array}{c}\text { Impedance } \\
(\mathbf{o h m s})\end{array}$ & $\begin{array}{c}\text { Lead tip } \\
\text { location }\end{array}$ \\
\hline 1 & 60 & $1.5 \pm 0.3^{*}$ & $616 \pm 14$ & Basal lateral \\
2 & 100 & $2.6 \pm 1.2$ & $1033 \pm 38$ & Basal lateral \\
3 & 100 & $3.4 \pm 1.2$ & $1007 \pm 35$ & Basal lateral \\
4 & 80 & $5.9 \pm 1.0$ & $811 \pm 22$ & Mid anterior \\
5 & 60 & $1.7 \pm 0.2$ & $1932 \pm 88$ & Basal posterior \\
6 & 100 & $1.6 \pm 0.4$ & $1600 \pm 80$ & Basal posterior \\
7 & 40 & $0.8 \pm 0.3$ & $652 \pm 20$ & Basal posterior \\
8 & 100 & $5.3 \pm 1.4$ & $829 \pm 85$ & Mid lateral \\
\hline
\end{tabular}

*Mean \pm 1 standard error of the mean. 
for administering retrograde cardioplegia via a CS cannula. The cardioplegia cannula not only accesses the CS, but it also it serves as a guiding sheath to direct the LV lead into a coronary branch vein, thereby addressing two major challenges to successful LV lead implantation in permanent cardiac resynchronization therapy. ${ }^{23}$ Without using fluoroscopic imaging, LV capture was achieved in $80 \%$ of lead placement attempts, and LV capture without diaphragmatic stimulation was achieved in 7 of the 8 animals.

In the majority of cases, the LV lead was in a lateral or posterior position, which are considered to be generally favorable positions for BiVP. ${ }^{24} \mathrm{We}$ found that, in the majority of failures to capture the LV, the LV lead had coursed into the left hemiazygous vein. This problem would not arise in humans, as the left hemiazygous vein drains directly into the CS in pigs but not humans. ${ }^{25}$

The model used here is only an approximation of the conditions during cardiac surgery, as cardiopulmonary bypass and cardioplegia were not used. Extension of the described technique to clinical reoperations would require a number of modifications. First, the LV lead would need to be introduced immediately following the last dose of retrograde cardioplegia and immediately before removal of the cardioplegia cannula. Next, final lead positioning and threshold testing would ideally be done on partial bypass, when electrophysiologic properties of the myocardium have recovered toward normal. Final lead positioning should also be done immediately before weaning from bypass, when the heart is maximally filled. This latter step would avoid lateral displacement of the right atrial wall by volume infusion from pulling the LV lead out of its optimized position.

Perioperative cardiac resynchronization is also being studied in pediatric patients undergoing surgery for congenital heart disease. ${ }^{26,27}$ This technique may provide an alternative approach to multi-site pacing in such patients.

Use of intraoperative transesophageal echocardiography may improve the success rate of LV lead placement. ${ }^{28}$ In the future, hybrid operating rooms offering fluoroscopic imaging will refine vein selection and lead localization. Furthermore, specialized endocardial LV leads and lead delivery systems, designed specifically for temporary BiVP via the CS, may further improve the efficacy and safety of this approach. The safety and feasibility of this technique warrants further study in human subjects undergoing reoperative cardiac surgery.

\section{References}

1. Cazeau S, Leclercq C, Lavergne T, Walker S, Varma C, Linde C, et al. Effects of multisite biventricular pacing in patients with heart failure and intraventricular conduction delay. N Engl J Med. 2001;344:873-80.

2. Abraham WT, Fisher WG, Smith AL, Delurgio DB, Leon AR, Loh E, et al. Cardiac resynchronization in chronic heart failure. $N$ Engl J Med. 2002;346: 1845-53.
3. Bristow MR, Saxon LA, Boehmer J, Krueger S, Kass DA, De Marco T, et al Cardiac-resynchronization therapy with or without an implantable defibrillator in advanced chronic heart failure. N Engl J Med. 2004;350:2140-50.

4. Cleland JG, Daubert JC, Erdmann E, Freemantle N, Gras D, Kappenberger L, et al. The effect of cardiac resynchronization on morbidity and mortality in heart failure. N Engl J Med. 2005;352:1539-49.

5. Epstein AE, DiMarco JP, Ellenbogen KA, Estes NA 3rd, Freedman RA, Gettes LS, et al. ACC/AHA/HRS 2008 Guidelines for Device-Based Therapy of Cardiac Rhythm Abnormalities. Circulation. 2008;117:e350-408.

6. Kass DA, Chen CH, Curry C, Talbot M, Berger R, Fetics B, et al. Improved left ventricular mechanics from acute VDD pacing in patients with dilated cardiomyopathy and ventricular conduction delay. Circulation. 1999;99:1567-73.

7. Nelson GS, Berger RD, Fetics BJ, Talbot M, Spinelli JC, Hare JM, et al. Left ventricular or biventricular pacing improves cardiac function at diminished energy cost in patients with dilated cardiomyopathy and left bundle-branch block. Circulation. 2000;102:3053-9.

8. Christakis GT, Weisel RD, Fremes SE, Ivanov J, David TE, Goldman BS, et al Coronary artery bypass grafting in patients with poor ventricular function. Cardiovascular Surgeons of the University of Toronto. J Thorac Cardiovasc Surg. 1992;103:1083-91

9. Risum O, Nitter-Hauge S, Abdelnoor M, Levorstad K, Arafa O, Svennevig JL. Mortality and morbidity after coronary artery bypass surgery related to preoperative left ventricular ejection fraction: a follow-up study. Eur Heart J. 1996;17:874-9.

10. Saxon LA, Kerwin WF, Cahalan MK, Kalman JM, Olgin JE, Foster E, et al Acute effects of intraoperative multisite ventricular pacing on left ventricular function and activation/contraction sequence in patients with depressed ventricular function. J Cardiovasc Electrophysiol. 1998;9:13-21.

11. Weisse U, Isgro F, Werling Ch, Lehmann A, Saggau W. Impact of atriobiventricular pacing to poor left-ventricular function after CABG. Thorac Cardiovasc Surg. 2002;50:131-5.

12. Berberian G, Quinn TA, Kanter JP, Curtis LJ, Cabreriza SE, Weinberg AD, et al Optimized biventricular pacing in atrioventricular block after cardiac surgery. Ann Thorac Surg. 2005;80:870-5.

13. Dzemali O, Bakhtiary F, Dogan S, Wittlinger T, Moritz A, Kleine P. Perioperative biventricular pacing leads to improvement of hemodynamics in patients with reduced left-ventricular function-interim results. Pacing Clin Electrophysiol. 2006;29:1341-5.

14. Schmidt C, Frielingsdorf J, Debrunner M, Tavakoli R, Genoni M Straumann E, et al. Acute biventricular pacing after cardiac surgery has no influence on regional and global left ventricular systolic function. Europace. 2007;9:432-6.

15. Pichlmaier M, Bagaev E, Lichtenberg A, Teebken O, Klein G, Niehaus M, et al Four-chamber pacing in patients with poor ejection fraction but normal QRS durations undergoing open-heart surgery. Pacing Clin Electrophysiol. 2008;31: 184-91.

16. Muehlschlegel JD, Peng YG, Lobato EB, Hess PJ Jr, Martin TD, Klodell CT Jr Temporary biventricular pacing postcardiopulmonary bypass in patients with reduced ejection fraction. J Card Surg. 2008;23:324-30.

17. Flynn M, Dark JH, McComb JM. Biventricular pacing after cardiac surgery. J Thorac Cardiovasc Surg. 2009;138:259-60.

18. Hanke T, Misfeld M, Heringlake M, Schreuder JJ, Wiegand UK, Eberhardt F. The effect of biventricular pacing on cardiac function after weaning from cardiopulmonary bypass in patients with reduced left ventricular function: a pressurevolume loop analysis. J Thorac Cardiovasc Surg. 2009;138:148-56.

19. Yau TM, Fedak PW, Weisel RD, Teng C, Ivanov J. Predictors of operative risk for coronary bypass operations in patients with left ventricular dysfunction. J Thorac Cardiovasc Surg. 1999;118:1006-13.

20. Amirhamzeh MM, Dean DA, Jia CX, Cabreriza SE, Starr JP, Sardo MJ, et al. Iatrogenic myocardial edema: increased diastolic compliance and time course of resolution in vivo. Ann Thorac Surg. 1996;62:737-43.

21. Rabkin DG, Cabreriza SE, Curtis LJ, Mazer SP, Kanter JP, Weinberg AD, et al Load dependence of cardiac output in biventricular pacing: right ventricular pressure overload in pigs. J Thorac Cardiovasc Surg. 2004;127:1713-22.

22. Kenny JE, Berberian G, Rabkin DG, Cabreriza SE, Quinn TA, Curtis LJ, et al. Ethanol induction of complete heart block in swine. J Surg Res. 2006;132: 142-6.

23. Saxon LA, De Marco T. Resynchronization therapy for heart failure, expert consensus statement. Available from http://www.hrsonline.org/Policy/ClinicalGuidelines/ upload/resynch_therapy_HF.pdf (in Heart Rhythm Society website, 2005). 
24. Murphy RT, Sigurdsson G, Mulamalla S, Agler D, Popovic ZB, Starling RC, et al. Tissue synchronization imaging and optimal left ventricular pacing site in cardiac resynchronization therapy. Am J Cardiol. 2006;97:1615-21.

25. Gilbert SG. The circulatory system. In: Gilbert SG, ed. Pictorial anatomy of the fetal pig. 2nd ed. Seattle: University of Washington Press; 1966:49.

26. Rhee EK. Cardiac resynchronization therapy in pediatrics: emerging technologies for emerging indications. Curr Treat Options Cardiovasc Med. 2005;7:399-409.
27. Bacha EA, Zimmerman FJ, Mor-Avi V, Weinert L, Starr JP, Sugeng L, et al. Ventricular resynchronization by multisite pacing improves myocardial performance in the postoperative single-ventricle patient. Ann Thorac Surg. 2004; 78:1678-83.

28. Artrip JH, Sukerman D, Dickstein ML, Spotnitz HM. Transesophageal echocardiography guided placement of a CS pacing lead. Ann Thorac Surg. 2002;74: 1254-6.

Access to The Journal of Thoracic and Cardiovascular Surgery Online is reserved for print subscribers!

Full-text access to The Journal of Thoracic and Cardiovascular Surgery Online is available for all print subscribers. To activate your individual online subscription, please visit The Journal of Thoracic and Cardiovascular Surgery Online, point your browser to http://www.mosby.com/jtcvs, follow the prompts to activate your online access, and follow the instructions. To activate your account, you will need your subscriber account number, which you can find on your mailing label (note: the number of digits in your subscriber account number varies from 6 to 10). See the example below in which the subscriber account number has been circled:

\section{Sample mailing label}

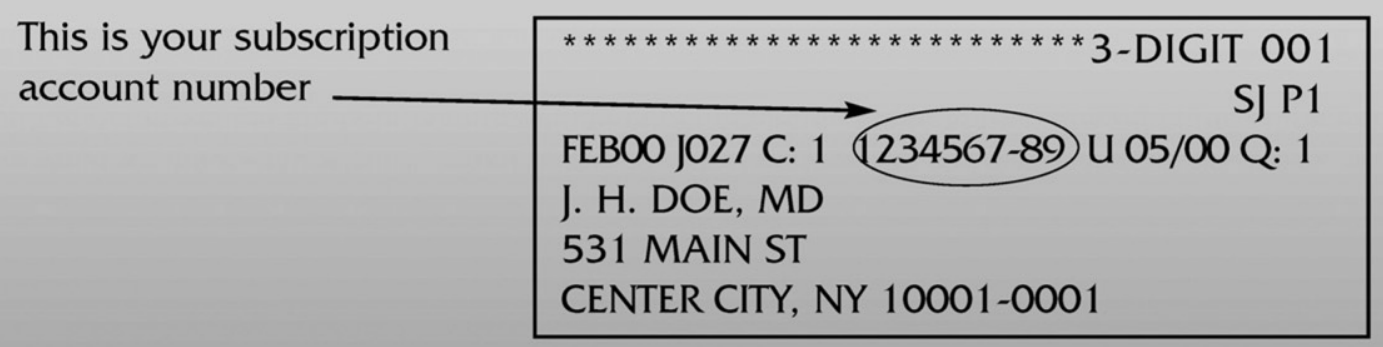

Personal subscriptions to The Journal of Thoracic and Cardiovascular Surgery Online are for individual use only and may not be transferred. Use of The Journal of Thoracic and Cardiovascular Surgery Online is subject to agreement to the terms and conditions as indicated online. 